\title{
Yaz ve Kış Aylarını İçeren Dönemlerde Yaş ve Cins Gruplarına Göre D Vitamin [25(OH)D3] Düzey Değişimleri
}

\section{Changes of Vitamin [25 (OH) D3] Levels According to Age and Gender Groups in the Period of Summer and Winter.}

\section{Metin KILINÇ ${ }^{1}$, Hatice SAĞER ${ }^{2}$, Eda GANIYUSUFOĞLU ${ }^{3}$, Yeliz DOBOĞLU ${ }^{2}$, Nazlı ÜLKER HANÇER ${ }^{4}$}

\author{
${ }^{1}$ Prof. Dr. Kahramanmaraş Sütçü İmam Üniversitesi Tip Fakültesi Tibbi Biyokimya Anabilim Dalı, KAHRAMANMARAŞ \\ ${ }^{2}$ Kimyager. Kahramanmaraș Sütçü İmam Üniversitesi Sağllk Bilimleri Enstitüsü Tibbi Biyokimya Anabilim Dall, KAHRAMANMARAȘ \\ ${ }^{3}$ Ph D. Kahramanmaraş Sütçü İmam Üniversitesi Fen Bilimleri Enstitüsü Biyomühendislik ve Sistemleri Anabilim Dalı,KAHRAMANMARAŞ \\ ${ }^{4}$ Öğ. Gör. Sinop Üniversitesi Boyabat Meslek Yüksekokulu, SİNOP
}

\section{Öz}

Amaç: D vitamini [25(OH)D3] insan sağlığı açısından önemli fonksiyonlara sahiptir. Bu araştırmada yaz ve kış aylarını içeren dönemlerde yaş ve cins gruplarına göre 25(OH)D3 laboratuvar verilerinin geriye dönük olarak incelenmesiyle ne oranda değişim gösterdiğinin ortaya konulması amaçlandı.

Gereç ve Yöntem: Çalıșmaya $0-5,5-12,13-18,19-49,50-90$ yaş aralığında bulunan kadın ve erkek olgular alındı. Bu amaçla Temmuz-Ekim döneminde 354 erkek ve 1105 kadın olmak üzere toplam 1459 kişi, Kasım-Mart döneminde ise 544 erkek ve 1579 kadın olmak üzere toplam 2123 kişi ve genel toplamda 3582 kişinin 25(OH)D3 düzeyleri geriye dönük olarak hastanemiz biyokimya laboratuvar otomasyon verilerinden taranarak incelendi. EDTA'lı tüplere alınan kan örnekleri, ön işlem sonrası Thermo uHPLC (Ultra high performans likit kromatografisi) cihazında kalibrasyon ve control sonuçlarının uygun bulunmasını takiben analizleri gerçekleştirildi.

Bulgular: Değişik yaş ve cins gruplarında güneşli günlerin uzun ve çok sayıda olduğu yaz ayları ile güneşli günlerin kısa ve az sayıda olduğu kış aylarını içeren dönemlerdeki 25(OH)D3 düzeylerinin otomasyon verileri taranmıştır. Taramada cut-off değeri $20 \mathrm{ng} / \mathrm{dl}$ (sınır değer) alınmıştır. Verilerin arasındaki farkın anlamlılığı ortaya konmuştur. Buna göre tüm yaş grupları göz önüne alındığında yaz aylarına göre kış aylarında ortalama olarak erkeklerde $\% 36.4$, kadınlarda ise \% 38.2 oranında bir azalmanın olduğu gözlenmektedir.

Sonuç: Yapılan bu çalışma ile kış aylarında D vitamin düzeylerinde 1/3'e varan oranlarda azalmanın olduğu gözlemlenmiştir. Buna göre $20 \mathrm{ng} / \mathrm{ml}$ 'nin altındaki olguların güneş ışı̆̆ından yeterince faydalanmadıkları bu nedenle güneşli günlerde yeterince güneş ışı̆̆gna maruz kalmaları veya $D$ vitamini desteği almaları önerilebilir.

Anahtar Kelimeler: Vitamin D, yaş grupları, mevsimsel değişim.

\section{Abstract}

Objective: Vitamin D has important implications for human health. The aim of this research was to investigate retrospectively how the laboratory data of vitamin $\mathrm{D}$ level changes according to sex and age groups during winter and summer months.

Materials and Methods: Study groups composed of woman and men were formed according to age groups of 0-4 years, 5-12 years, 13-18 years, 19-49 years, 50-90 years. For this purpose, between July and October, the data of 354 male and 1105 female patients, of a total of 1459 subjects were taken. Between November and March, data of 544 men and of 1579 women, of total 2123 persons were analyzed. In total, data of 3582 personswere screened retrospectively from laboratory automation data. Blood samples (Containing EDTA) were analyzed by Thermo uHPLC (Ultra High Performance Liquid Chromatography) after preliminary processing the results of calibration and control are found appropriate.

Results: Vitamin D levels of automation data were scanned in different age and gender groups in summer months where sunny days were long and numerous and in winter days where sunny days were short and fewer. The cut-off value in the scan was accepted as $20 \mathrm{ng} / \mathrm{dL}$ (limit value). Accordingly, when all age groups were considered,there was a decrease of $36.4 \%$ for men and $38.2 \%$ for women in Vitamin D levels in winter months compared to that in summer months.

Conclusion: In this research, it has been observed that vitamin D levels in winter months decrease by a rate of $1 / 3$. Accordingly, when vitamin D levels are below $20 \mathrm{ng} / \mathrm{ml}$ due to inadequate exposure to sunlight, it may be recommended that people be exposed to sunlight in sunny days or take $\mathrm{D}$ vitamin preparations.

Key Words: Vitamin D, age groups, seasonal changes.

\section{GİRIS}

D vitamini (D vit.) yağda çözünen vitamin grubu içerisinde olup canlılarda özellikle kalsiyum, fosfor metabolizması, immün sistem ve daha birçok yararlı fonksiyonlara sahip bir moleküldür. Kalsiyum ve fosfor vücutta kemik, kas, sinir sistemi, enerji metabolizması gibi çok önemli hayati fonksiyonlarda görev almaktadır. D vit.nin özellikle bağırsaklardan kalsiyum $(\mathrm{Ca} 2+)$ emilimi üzerinde etkisinin varlığ 1 bilinmekle birlikte son y1llarda $25(\mathrm{OH}) \mathrm{D} 3$

İletişim: Dr. Metin Kılınç, KSÜ Tip Fakültesi Tibbi Biyokimya Anabilim Dalı, Kahramanmaras

DOI:

$10.17517 / \mathrm{ksutfd} .416338$ vitamininin sitokin gibi rol oynayarak konakçının immün yanıtlarının düzenlenmesinde önemli role sahip 1,25(OH)2D3 düzeylerinde artış yapmaktadır (1). 1,25(OH)2D3'ün bir şekilde hücre proliferasyonu, diferansiyasyonu, apoptozisi ve anjiyogenezisi kontrol eden genler de dahil olmak üzere 200 den fazla gen üzerinde kontrol fonksiyonunun bulunduğu bildirilmiștir. Ayrıca vitamin D’nin normal hücrelerde ve kanser hücrelerinde hücre proliferasyonunu azalttığı da

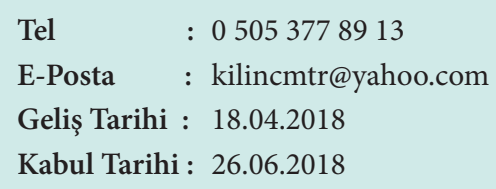


belirtilmektedir (1-3). Güneşten gelen ultraviyole (UVB) 1şınları (290-320 nm dalga boyundaki) etkisiyle deride (Epidermis ve dermisde) bulunan kolesterol türevi olan kolekalsiferolü previtamin D3'e dönüştürmekte ve bu da vücut 1sısı ile izomerize olarak Vit. D3 oluşturmaktadır. Vit. D3, vitamin D bağlayıcı protein ile dolaşım yoluyla karaciğere ulaşarak 25 . karbon atomunun hidroksillenmesiyle 25(OH)D3 vitaminine daha sonra böbreklerde tekrar molekülün 1. karbon atomunun hidroksillenmesiyle 1,25(OH)2D3 vitaminine dönüşmektedir. Daha fazla oranda UVB ışınlarına maruz kalmanın previtamin D3'ün etkisiz moleküller olan takisterol ve lunisterole dönüştürdüğü belirtilmektedir (3-6). 1,25(OH)2D3Vit.D reseptörleri (VDR) ile etkileşime girmekte, böylece ince bağırsaktaki hücrelerde kalsiyum kanal proteinleri, kalsiyum bağlayıcı protein ve diğer proteinlerin ekspresyonlarını arttırmak suretiyle barsak lümeninden dolaşıma kalsiyum geçişini sağlamaktadır. Aynı zamanda kemikte bulunan VDR reseptörlerine bağlanmak suretiyle osteoklast prekürsörlerinin olgun osteoklast haline gelmeleriyle kemikten kalsiyum mobilizasyonuna neden olarak kan kalsiyum düzeyinin idamesinde de önemli rolleri bulunmaktadır (6). 25(OH)D3 düzeylerinin vücutta $\mathrm{D}$ vitamin durumunun en iyi göstergesi olduğu kabul edilmektedir (7). Yarı ömrü yaklaşık olarak 2-3 hafta kadar olup endojen ve eksojen üretimin göstergesi 25(OH)D3vitamin düzeyidir. 25(OH)D3vit; <20 ng/ml D vit eksikliği, 21-29 ng/ml: D vit yetersizliği, D vit $>30 \mathrm{ng} / \mathrm{ml}$ düzeyin yeterli olduğunu göstermektedir (8). Arzu edilen kan düzeyi 40-60 ng/ml dir. Normal şartlarda D vit.'in vücutta sentezinin \% 95’i güneş ışınlarının etkisiyle deride sentez yoluyla olmaktadır. Dışarıdan preparat olarak alınmadıkça yiyeceklerle D vitamini alımı önemli miktarlarda değildir. Konu ile ilgili araştırmacılar D vit. üretimi için haftada $2-3 \mathrm{kez}$ el, kol ve yüzün 5-15 dk güneş ışı̆̆ına maruz bırakılmasının ihtiyacı karşılayabileceğini belirtmektedirler (1). 1,25(OH)2D3 barsaklardan Ca2+ emilimine etki ederek \% 10-15 den \% 30-40'e kadar, fosfor emilimini ise \% 50-60'dan \% 80’e kadar arttırdiğ 1 bilinmektedir. UV indeks düşüklüğünün $\mathrm{D}$ vit azalmasına neden olması muhtemeldir. UV indeksi güneş ışınlarının yakın ve en dik olduğu zamanlarda yüksek düzeyine ulaşmaktadır. UV indeksinin 0-15 arasındaki değerleri şiddet göstergesini ifade edilmekte ve gün boyunca değişim göstermektedir. Bu indeksten anlaşılan UV indeksi ne kadar yüksek ise cilde zarar verme etkisi o oranda yüksek ve süresi de o kadar kısadır, 1 UV I = 0.025 W/ m2'dir (9). UVB den faydalanma ülkelerin bulundukları enlemlere göre de değişim göstermektedir (10).

Değişik yönden farklı yararlarının olduğu bilinen D vit. için yeterli güneş ışığına ihtiyaç bulunmaktadır. Ancak D vit. üretimini deride etkileyen faktörlere bakıldığında bunların yaş, derideki pigmentasyonun derecesi, sıkı giyinme, güneş ışı̆̆ına maruz kalma süresi, topikal güneş koruyucuların kullanımı, kapalı havalar, mevsimler, enlemler gibi önemli unsurların olduğu görülmektedir. Kandaki D vitamin düzeyleri besinlerle alınan miktardan ziyade çoğunlukla deride sentezlenen miktarla ilişkilidir. Bölgemizde güneş ışınlarına maruz kalmanın bu konudaki önemi ve güneş ışınlarının çok ve uzun olduğu dönemlerle az ve kısa olduğu dönemler arasındaki $\mathrm{D}$ vitamin düzey değişikliklerinin ne oranda olduğunun araştırılması planlanmıştır.

\section{GEREÇ VE YÖNTEM}

$\mathrm{Bu}$ geriye dönük çalışma Kahramanmaraş Sütçü İmam Üniversitesi Sağlık Uygulama ve Araştırma Hastanesi
Biyokimya Laboratuvarı otomasyon (Enlil) verileri taranmak suretiyle gerçekleştirilmiştir. Kahramanmaraş coğrafi olarak Doğu Akdeniz bölgesinde yer alması dolayısıyla yağmurlu günler dışında her mevsimde güneşin etkili olduğu bir yerdir. Temmuz-Ekim ayları dahil dönemde 354 erkek ve 1105 kadın olmak üzere toplam 1459 kişi, Kasım-Mart ayları dahil dönemde ise 544 erkek ve 1579 kadın olmak toplam 2123 kişi ve genel toplamda 3582 kişinin D vit düzey kayıtları incelenmiştir. Serum düzeyinin $<20 \mathrm{ng} / \mathrm{ml}$ olması D vit eksikliği olarak kabul edildi. Hastalar yaşlarına göre 0-5, 5-12, 13-18, 19-49, 50-90 olmak üzere 5 yaş aralığında incelendi. Yaş grubu belirlenmesinde Wintrobe's Clinical Haematology kitabı kaynak olarak kullanıldı (11). Buna göre yaş gruplarına göre yaz aylarındaki D vit. eksikliği oranı ile kış aylarındaki $\mathrm{D}$ vit. eksikliği oranları arasındaki fark değerlendirildi. Hastanemizde tüm hastalar için $\mathrm{D}$ vit düzeyi belirlenmesi EDTA'lı kan örneklerinde UHPLC (Ultra yüksek basınçlı sıvı kromatografisi) Thermo Scientific (ABD) cihazı kullanılmak suretiyle yapildı. Sayısal verilerin elde edilmesinde Enlil program direct olarak kullanıld, hesaplamalar IBM SPSS 21.0 programında tanımlayıcı işlemler ve ki-kare testi kullanılmak suretiyle yapıldı. Gruplar arası karşılaştırmalarda $\mathrm{p}<0.05$ istatistiksel olarak anlamlı olarak kabul edildi.

\section{SONUÇLAR}

Yaş ve cins grupları göz önüne alınarak temmuz ve kasım aylarını içeren dönemde D vit. düzeylerinin $20 \mathrm{ng} /$ $\mathrm{ml}$ nin üzerinde ve altında olan olguların sayı ve yüzdeleri Tablo 1 de, Kasım ve mart aylarını içeren dönemdeki değerleri ise Tablo 2 de gösterilmiştir. Her iki tablo karşılaştırıldığında (Tablo 3) güneşli mevsimlerin olduğu dönemdeki $\mathrm{D}$ vit $>20 \mathrm{ng} / \mathrm{ml}$ değerlerin oranı ortalama olarak erkek olgularda \% 95.0 iken, güneşin az olduğu ayları içeren dönemdeki oran \% 58.6'ya düşmektedir $(\mathrm{p}<0,001)$. Aradaki farkın \% $36.4(\mathrm{p}<0,001)$ kadar bir azalma yönünde olduğu, kadın olgularda ise bu farkın \% 38,2 ( $\mathrm{p}<0,001)$ gibi yüksek bir farklılığın olduğunu göstermektedir. Tablo 3 incelendiğinde mevsimsel farkın en az olduğu yaş grubu 0-5.0 yaş arasındaki erkek ve kız çocukları iken en fazla olduğu yaş grubu erkeklerde 5090 arası yaş grubu (\% 44.7, p<0,001), kadın olgularda ise 19-49 yaş doğurganlık çağında bulunanlarda (\% 44.0, $\mathrm{p}<0,001)$ olduğu görülmekteydi.

\section{TARTIŞMA}

Vit D’nin yiyeceklerle alımı oldukça sınırlı (\% 10>) olduğu için güneş 1şınlarındaki UVB nin insan sağlığı için önemi ön planda görülmektedir. İnsanlardaki D vit düzeyinin $30 \mathrm{ng} / \mathrm{ml}$ düzeyinde olması çoğu araştırmacı tarafından vücut fonksiyonları için yeterli görünmektedir $(12,13)$. Güneş 1şınları yeterli değilse Dünya Sağlık Örgütü (WHO) önerdiği dozlarda (Günlük 200-400 IU) dişardan desteklenmesi gerektiği yönündedir (14). Ancak bazı araştırmacılar ileri yaşlardaki kalça kırıklarının önlenmesi açısından günlük dozun 700-800 IU düzeyinde olması gerektiğini düşünmektedir (15). Yetişkinlerde günlük alınan dozun 2000 IU'nin üzerine çıkması durumunda toksik belirtilerin görüleceği bildirilmektedir (12). Dolayısıyla D vit. konusunda duyarlı olunduğu kadar doz ayarlamada da bilinçli olunmasında yarar görülmektedir. $\mathrm{D}$ vit düzeyinin mevsimsel değişimlere bağlı olduğu 
Tablo 1. Temmuz-Kasım ayları dahil dönemde olguların sınır değer üzerinde ve altında ölçülen D vit. sayı ve yüzde oranları

\begin{tabular}{|l|l|l|l|l|}
\hline Yaş Grubu & $\begin{array}{l}\text { Erkek olgu- } \\
\text { lar }\end{array}$ & $\begin{array}{l}\text { Kadın olgu- } \\
\text { lar }\end{array}$ & & \\
\hline & D vit>20 & D vit<20 & D vit $>20$ & D vit<20 \\
\hline $\mathbf{0 - 5}$ & $42(\% 97,7)$ & $1(\% 1,3)$ & $23(\% 100,0)$ & - \\
\hline $\mathbf{5 - 1 2}$ & $20(\% 95,2)$ & $1(\% 4,8)$ & $24(\% 100,0)$ & - \\
\hline $\mathbf{1 3 - 1 8}$ & $17(\% 94,4)$ & $1(\% 5,6)$ & $44(\% 91,7)$ & $4(\% 8,3)$ \\
\hline $\mathbf{1 9 - 4 9}$ & $152(\% 94,4)$ & $9(\% 5,6)$ & $591(\% 91,6)$ & $54(\% 8,4)$ \\
\hline $\mathbf{5 0 - 9 0}$ & $106(\% 95,5)$ & $5(\% 4,5)$ & $336(\% 92,1)$ & $29(\% 7,9)$ \\
\hline Genel & $337(\% 95.0)$ & $17(\% 5.0)$ & $1018(\% 91.5)$ & $87(\% 8,5)$ \\
\hline
\end{tabular}

Tablo 2. Kasım-Mart ayları dâhil dönemde olguların sınır değer üzerinde ve altında ölçülen D vit. Sayı ve yüzde oranları

\begin{tabular}{|l|l|l|l|l|}
\hline Yaş Grubu & $\begin{array}{l}\text { Erkek olgu- } \\
\text { lar }\end{array}$ & $\begin{array}{l}\text { Kadın olgu- } \\
\text { lar }\end{array}$ & & \\
\hline & D vit $>20$ & D vit<20 & D vit $>20$ & D vit<20 \\
\hline $0-5$ & $69(\% 76,7)$ & $21(\% 23,3)$ & $57(\% ~ 80,3)$ & $14(\% 19,7)$ \\
\hline $5-12$ & $33(\% 63,5)$ & $19(\% 36,5)$ & $37(\% 53,6)$ & $32(\% 46,4)$ \\
\hline $13-18$ & $35(\% 63,6)$ & $20(\% 36,4)$ & $34(\% 54,8)$ & $28(\% 45,2)$ \\
\hline $19-49$ & $115(\% 51,1)$ & $100(\% 48,9)$ & $434(\% 47,6)$ & $477(\% 52,4)$ \\
\hline $50-90$ & $67(\% 50,8)$ & $65(\% 49,2)$ & $280(\% 60,1)$ & $186(\% 39,9)$ \\
\hline Genel & $319(\% 58,6)$ & $225(\% 41,4)$ & $842(\% 53,3)$ & $737(\% 46,7)$ \\
\hline
\end{tabular}

Tablo 3. Temmuz-Ekim ayları ve Kasım-Mart ayları dâhil bu dönemlerde $D$ vit $>20$ hasta yüzdelerinin yaş gruplarına ve cinsiyete göre D vit eksikliği açısından dağılımı

\begin{tabular}{|c|c|c|c|c|}
\hline Yaş Grubu & Erkek olgular & Kadın olgular & & \\
\hline & $\begin{array}{l}\text { Temmuz-Ekim } \\
\text { ayları } \\
\text { D vit }>20 \\
\text { Yüzde oranları }\end{array}$ & $\begin{array}{l}\text { Kasım-Mart } \\
\text { ayları } \\
\text { D vit }>20 \\
\text { Yüzde oranları }\end{array}$ & $\begin{array}{l}\text { Temmuz-Ekim } \\
\text { ayları } \\
\text { D vit }>20 \\
\text { Yüzde oranları }\end{array}$ & $\begin{array}{l}\text { Kasım-Mart } \\
\text { ayları } \\
\text { D vit }>20 \\
\text { Yüzde oranları }\end{array}$ \\
\hline $0-5^{*}$ & $\% 97,7$ & $\% 76,7^{*}$ & $\% 100,0$ & $\% 80,3^{*}$ \\
\hline $5-12^{*}$ & $\% 95,2$ & $\% 63,5^{\star}$ & $\% 100,0$ & $\% 53,6^{*}$ \\
\hline $13-18^{\star}$ & $\% 94,4$ & $\% 63,6^{*}$ & $\% 91,7$ & $\% 54,8^{*}$ \\
\hline $19-49^{*}$ & $\% 94,4$ & $\% 51,1^{\star}$ & $\% 91,6$ & $\% 47,6^{*}$ \\
\hline $50-90^{\star}$ & $\% 95,5$ & $\% 50,8^{\star}$ & $\% 92,1$ & $\% 60,1^{\star}$ \\
\hline Genel $^{*}$ & $\% 95.0$ & $\% 58,6^{*}$ & $\% 91.5$ & $\% 53,3^{*}$ \\
\hline
\end{tabular}

bilinmekle birlikte, bu düzeye bağlı olarak bazı kronik hastalıkların belirtilerindeki değişimlerin olduğu da bildirilmiştir (16). Örneğin astma hastalarında kış aylarındaki astma kontrol testleri ile D vit. düzeylerinin negatif korelasyon gösterdiği vurgulanmıştır (16). Bununla birlikte özellikle tip 1 diyabet gelişiminde D vit’nin önleyici etkisinin varllğı üzerinde durulmuştur (17). Ayrıca birçok kanser türlerini ile D vit. arasında ters yönde bir iliş̧kinin varlığından bahseden çok sayıda makale de bulunmaktadır $(6,8,18,19)$. Kapalı salonlarda ve açık alanlarda çalışan atletlerde mevsimlere göre $\mathrm{D}$ vit. ölçümleri yapılmış ve kapalı ortamlarda çalışanlarda, çalışmayanlara oranla D vit. düzeylerinde anlamlı düşüklüğün olduğu gözlenmiştir (20). D vit. mevsimsel değişim gösterdiği şeklindeki bilgi çoğu araştırmacı tarafından paylaşılmaktadır. Ancak yörelere göre ne oranda değişimin olduğu çeşitli faktörlere bağlanmaktadır. $\mathrm{Bu}$ faktörler yaşanılan yerin coğrafi konumu, geleneksel giyim tarzı, mevsimler, yaş, kapalı ve açık alanlarda bulunma, beslenme şekli, sosyokültürel durum ve $\mathrm{D}$ vit. destekleri gibi nedenlerden etkilenmektedir. Hekimsoy ve ark tarafından ülkemizde yapılan bir çalışmada, İç Ege bölgesinde kış sonu itibarı ile 20 yaş ve üzeri yetişkinlerde yapmış olduğu $\mathrm{D}$ vit. ölçümlerinde $\%$ 74.9 oranında $25(\mathrm{OH}) \mathrm{D}$ eksikliğinin $(<20 \mathrm{ng} / \mathrm{mL})$ olduğunu bildirilmiştir (21). Bizim çalışmamızda kış aylarını içeren dönemlerde $\mathrm{D}$ vit düzeylerinin yaz aylarına göre yarıya yakın oranlarda düştüğü gözlenmektedir. $\mathrm{D}$ vit eksikliği yaşlılarda, özellikle bakım evlerinde yaşayanlarda \% 70-100 civarlarına kadar yükselmektedir, $25 \mathrm{OH}$ D3 düzeylerinin görülmesi gereken oranların ancak yarısı kadar olduğu gözlenmiştir. Yaşlanma ile D vit. reseptör sayı (VDR) ve afinitesinde azalma meydana geldiğive bu nedenle 70 'li yaştakilerde D vit. sentezinin \% 25 kadar azaldığı bildirilmiștir (1). Orta yaş İngiliz vatandaşlar üzerinde yapılmış olan çalışmada sonbahar ve kış aylarında $\mathrm{D}$ vit. düzeylerinde belirgin bir düşmenin olduğunu belirtmişlerdir (22). Yapılan diğer bir çalışmada güneş işınlarından yararlanmanın önemini vurgulamak açısından, obez kişilerde hareket kısıtlılığından dolayı dıșarıda daha az bulunmalarından dolayı güneș ışı̆̆ından daha az faydalandıkları ve $D$ vit. düzeylerinin normal kişilere göre daha düşük olduğu belirtilmiştir (23). Güneș ıșınlarının yeterli miktarda alınmasının sağlık açısından çok sayıda faydaları olduğu farklı çalışmalarla ortaya konmuştur. Yaptığımız bu çalışma ile değişik yaş gruplarında kış aylarında D vit. düzeylerinde $1 / 3^{\prime}$ den $1 / 2$ 'ye varan oranlarda bir düşmenin olduğu gözlenmiş̦tir. Bu nedenle bu kişilerin D vit. düzeylerini özellikle kış aylarında ölçtürerek (Eğer $20 \mathrm{ng} / \mathrm{ml}$ den düşükse) gerekirse $\mathrm{D}$ vit. desteği almaları önerilmelidir. Daha iyisi kış ayı da olsa güneşli günlerde el, kol ve yüzün güneşe doğru tutulmasiyla bir miktar $D$ vit. oluşturulacağ 1 kanısının yerleştirilmesine katkıda bulunulmasının yararlı olacağına inanılmaktadır.

\section{KAYNAKLAR}

1. Sözen T. D hormonu: Güncel gelişmeler, Hacettepe Tip Dergisi 2011; 42:14-27.

2. Garland CF, Gorham ED, Mohr SB, Garland FC. Vitamin 
D for Cancer Prevention: Global perspective. Ann Epidemiol 2009; 19: 468-483.

3. Holick MF. Vitamin D: Its role in cancer prevention and treatment. Progress in Biophysics and Molecular Biology. 2006; 92: 49-59.

4. Wolpowitz D, Gilchrest BA. The vitamin D questions: How much do you need and how should youget it? J Am Acad Dermatol 2006; 54: 301-17.

5. De Luca H. Overview of general physiologic features and functions of vitamin D. Am J Clin Nutr. 2004; 80:1689S-1696S.

6. Holick, MF. Sunlight and vitamin D for bone health and prevention of autoimmune diseases, cancers, and cardiovascular disease. Am J Clin Nutr. 2004a; 80: 1678S-1688S.

7. Lips P. Which circulating level of 25-hydroxy vitamin $D$ is appropriate? Journal of Steroid Biochemistry\&Molecular Biology. 2004; 89-90: 611-614.

8. Holick MF. Vitamin D Status: Measurement, Interpretation, and Clinical Application. Ann Epidemiol 2009; 19: 73-78

9. Fioletov V, Kerr JB, Ferguson A. The UV index: definition, distribution and factors affecting it. Can J Public Health 2010; 101: 15-19.

10. O’Neill CM, Kazantzidis A, Ryan MJ, Barber N, Sempos CT, Durazo-Arvizu RA, et al. Seasonal Changes in Vitamin D-Effective UVB Availability in Europe and Associations with Population Serum 25-Hydroxyvitamin D.Nutrients. 2016; 30; 8(9).

11. Lee GR. Iron deficiency and iron deficiency anaemias. In:Lee GR, Bithelltc, Foerster J, Ahhens JW, Lukens JN, eds. Wintrobe's Clinical Haematology, 9th edn. London: Lea\&Febiger, 1993; 808-832.

12. Lehmann B, Meurer M. Vitamin D metabolism. Dermatologic Therapy, 2010; 23: 2-12.

13. Jones G. Pharmacokinetics of vitamin D toxicity. Am J Clin Nutr 2008: 88 (Suppl): 582S-586S.
14. Levine BS, Singer FR, Bryce GF, Mallon JP, Miller ON, Coburn JW. Pharmacokinetics and biologic effects of calcitriol in normal humans. J Lab Clin Med 1985; 105: 239-246.

15. World Health Organization. Diet, nutrition and preventing of chronic diseases. Geneva: World Health Organization, 2003.

16. Bischoff-Ferrari HA, Willett WC, Wong JB, Giovannucci E, Dietrich T, Dawson-Hughes B. Fracture prevention with vitamin D supplementation: a meta analysis of randomized controlled trials. JAMA 2005; 293: 2257-2264.

17. Batmaz SB, Arıkoğlu T, Tamer L, Eskandari G, Kuyucu S. Seasonal variation of asthma control, lung function tests and allergic inflammation in relation to vitamin D levels: a prospective annual study. Postepy Dermatol Alergol. 2018; 35: 99-105.

18. Maddaloni E, Cavallari I, Napoli N, Conte C. Vitamin D and Diabetes Mellitus. Send to Front Horm Res. 2018; 50: 161-176.

19. Liu Y, Wang X, Sun X, Lu S, Liu S. Vitamin intake and pancreatic cancer risk reduction: A meta-analysis of observational studies. Medicine (Baltimore). 2018; 97: e0114.

20. Kong P, Cai Q, Geng Q, Wang J, Lan Y, Zhan Y, et al. Vitamin intake reduces the risk of gastric cancer: meta-analysis and systematic review of randomized and observational studies. PLoS One. 2014; 30; 9(12):e116060.

21. Maruyama-Nagao A, Sakuraba K, Suzuki Y. Seasonal variations in vitamin $\mathrm{D}$ status in indoor and outdoor female athletes. Biomed Rep. 2016; 5: 113-117.

22. Hekimsoy Z, Dinç G, Kafesçiler S, Onur E, Güvenç Y, Pala T, et al. Vitamin D status among adults in the Aegean region of Turkey. BMC, Public Health 2010; 10: 782.

23. Hyppönen E, Power C. Hypovitaminosis D in British adults at age $45 \mathrm{y}$ : nation wide cohort study of dietary and life style predictors Am J Clin Nutr 2007; 85: 860-868.

24. Harel Z, Flanagan P, Forcier M, Harel D. Low Vitamin D Status Among Obese Adolescents: Prevalence and Response to Treatment. Journal of Adolescent Health 2011;48: 448-452. 